\title{
Cantharidin Impedes Activity of Glutathione $S$-Transferase in the Midgut of Helicoverpa armigera Hübner
}

\author{
Rashid Ahmed Khan ${ }^{1, \dagger}$, Ji Yuan Liu ${ }^{1, \dagger}$, Maryam Rashid ${ }^{1, \dagger}$, Dun Wang ${ }^{1,2, *}$ and \\ Ya Lin Zhang ${ }^{1, *}$
}

1 Key Laboratory of Plant Protection Resources and Pest Management, Ministry of Education, College of Plant Protection, Northwest A\&F University, Yangling 712100, Shaanxi, China; E-Mails: rashidpp2004@yahoo.co.uk (R.A.K.); liujiyuan@nwsuaf.edu.cn (J.Y.L.); smilejust9@yahoo.com (M.R.)

2 Institute of Entomology, Northwest A\&F University, Yangling 712100, Shaanxi, China

$\dagger$ These authors contributed equally to this work.

* Authors to whom correspondence should be addressed; E-Mails: wanghande@yahoo.com (D.W.); yalinzh@yahoo.com.cn (Y.L.Z.); Tel./Fax: +86-29-8709-2190 (D.W. \& Y.L.Z.).

Received: 17 December 2012; in revised form: 16 February 2013 / Accepted: 26 February 2013 / Published: 8 March 2013

\begin{abstract}
Previous investigations have implicated glutathione $S$-transferases (GSTs) as one of the major reasons for insecticide resistance. Therefore, effectiveness of new candidate compounds depends on their ability to inhibit GSTs to prevent metabolic detoxification by insects. Cantharidin, a terpenoid compound of insect origin, has been developed as a bio-pesticide in China, and proves highly toxic to a wide range of insects, especially lepidopteran. In the present study, we test cantharidin as a model compound for its toxicity, effects on the mRNA transcription of a model Helicoverpa armigera glutathione $S$-transferase gene (HaGST) and also for its putative inhibitory effect on the catalytic activity of GSTs, both in vivo and in vitro in Helicoverpa armigera, employing molecular and biochemical methods. Bioassay results showed that cantharidin was highly toxic to $H$. armigera. Real-time qPCR showed down-regulation of the HaGST at the mRNA transcript ranging from 2.5 to 12.5 folds while biochemical assays showed in vivo inhibition of GSTs in midgut and in vitro inhibition of rHaGST. Binding of cantharidin to HaGST was rationalized by homology and molecular docking simulations using a model GST (1PN9) as a template structure. Molecular docking simulations also confirmed
\end{abstract}


accurate docking of the cantharidin molecule to the active site of HaGST impeding its catalytic activity.

Keywords: glutathione S-transferases; Helicoverpa armigera; cantharidin; mRNA; molecular docking simulations

\section{Introduction}

Glutathione $S$-transferase (GST EC 2.5.1.18) is an important family of multifunctional isozymes found in all eukaryotes. One of the main metabolic functions of GST is to catalyse xenobiotics, including pesticides in the mercapturic acid pathway leading to the elimination of toxic compounds [1]. GSTs also convert a reactive lipophilic molecule into a water-soluble, non-reactive conjugate which may easily be excreted [2]. This family of enzymes has been implicated as one of the major mechanisms for neutralizing the toxic effects of insecticides in insects $[3,4]$.

In recent years, the management of Helicoverpa armigera, the American bollworm, has become increasingly difficult due to the development of resistance to various groups of insecticides, particularly pyrethroids and cyclodyienes [5]. H. armigera is an important polyphagous pest of cotton and many other crops of agricultural importance all over the world. In insects, GSTs provide an important defense mechanism against plant allelochemicals [6] as well as insecticides [7]. An increased level of GSTs has been regarded as causing organochlorine and organophosphorus insecticide resistance [8-14].

The active constituent of mylabris, cantharidin is produced by as many as 1500 different species of blister beetles, with the Spanish fly Cantharis vesicatoria probably being the best known source $[15,16]$. Cantharidin was first isolated by Robiquet, a French chemist in 1810. It has an important role in the ecology of different kinds of insects that use or produce it as a defense to preserve their eggs from predators [17].

Recently this defensive tool has been developed into a bio-pesticide and one of the formulations as an emulsifiable concentrate (EC) has been registered for the control of lepidopteran pests while other formulations of cantharidin and its analogues are under field trial for registration. Cantharidin as $1.0 \%$ EC has been tested for its environmental safety and toxicity was found to be within safe limits for ladybugs, quail and soil microorganisms [18]. The antifeedant activity of cantharidin and its toxicity was earlier established against armyworm, Mythimna separata [19]. Furthermore, inhibitory effect of cantharidin on GSTs was reported in M. separata [20]. However, its toxicity and inhibitory effect on GSTs in $H$. armigera have not yet been investigated in detail.

At present there is very little information about the toxicity mechanism of cantharidin to insects and its interaction with metabolizing enzymes, especially GSTs. In the present study, our aim was to investigate the effect of cantharidin on mRNA transcript of HaGST (GenBank accession no EF033109) and also its putative role in the inhibition of GSTs in H. armigera both in vivo and in vitro. For this purpose, we cloned a model $H$. armigera GST gene (HaGST) which was previously reported for its role in insect defense mechanism [21] and prokaryotically expressed it to get soluble recombinant 
protein, rHaGST. Homology modeling and molecular docking simulation techniques were employed to rationalize our experimental results.

\section{Results and Discussion}

\subsection{Bioassay}

Bioassay results showed an increase in levels of $H$. armigera mortality with time after feeding on cantharidin-treated artificial diet. The artificial diet incorporated cantharidin of $250 \mu \mathrm{g} \mathrm{g}^{-1}$ at 12,24 , 48, $72 \mathrm{~h}$ after treatment caused significant larval mortality of $23 \%, 41 \%$ and $69 \%$ and $98 \%$, respectively (Figure 1).

Figure 1. Mean percentage mortalities of $H$. armigera. Third-instar larvae were subjected to bioassay. Error bars show \pm SD among three replications. Number of third-instar larvae tested per treatment $(n=72)$.

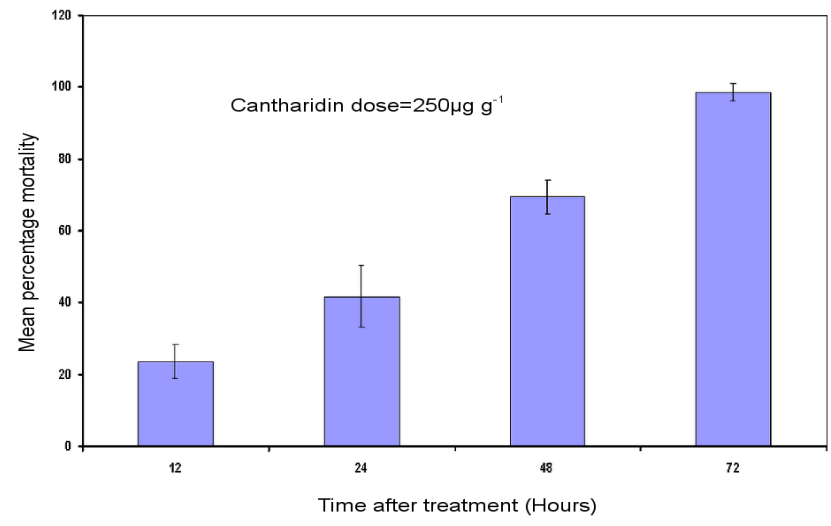

\subsection{SDS-PAGE Analysis}

The positive clones were transformed in BL-21 (DE-3) and protein expression induced by the addition of IPTG was detected initially by SDS-PAGE using standard protein molecular weight marker. The expected band was detected at $27 \mathrm{kDa}$ as the MW of the HaGST is about $24 \mathrm{kDa}$ and the pET-28a tag is about $3 \mathrm{kDa}$ (Figure 2). The expression of recombinant protein was detected by $6 \times$ His mouse monoclonal primary antibody on a PVDF membrane.

\subsection{Specific Activity of HaGST}

The inhibitory effects of cantharidin in vivo on GSTs enzyme within midguts dissected from larvae treated with sub-lethal dose of cantharidin is shown in Figure 3. A sub-lethal dose of $25 \mu \mathrm{g} \mathrm{g}^{-1}$ exerted inhibitory effects on the GSTs in midgut as compared to the untreated control. Data showed that the specific activity of the GSTs tended to decrease in treatment from 24 to $96 \mathrm{~h}$, whereas specific activity tended to increase in untreated controls. The inhibitory effect on the activity at $96 \mathrm{~h}$ after treatment was 22.8 compared to $48.32 \mu \mathrm{M} \mathrm{min}{ }^{-1} \mathrm{mg}^{-1}$ of control. 
Figure 2. SDS-PAGE analysis of fusion protein. (A) Lane M, Protein weight marker; Lane1, DE-3; Lane 2, DE-3 + pET28a; Lane 3, DE-3 + pET28a-HaGST (without IPTG); Lane 4-6, expression level of the soluble fusion protein at 1-6 h; (B) Purified soluble rHaGST. Lane M, Protein weight marker; Lane 1, Purified rHaGST by $\mathrm{Ni}^{2+}$-nitrilotriacetate (NTA) column; Lane 2, non purified protein; (C) Immunoblotting of rHaGST with $6 \times$ His mouse monoclonal primary antibody. Lane M, Molecular weight marker; Lane 1, rHaGST detected by peroxidase conjugated goat anti-mouse IgG secondary antibody.
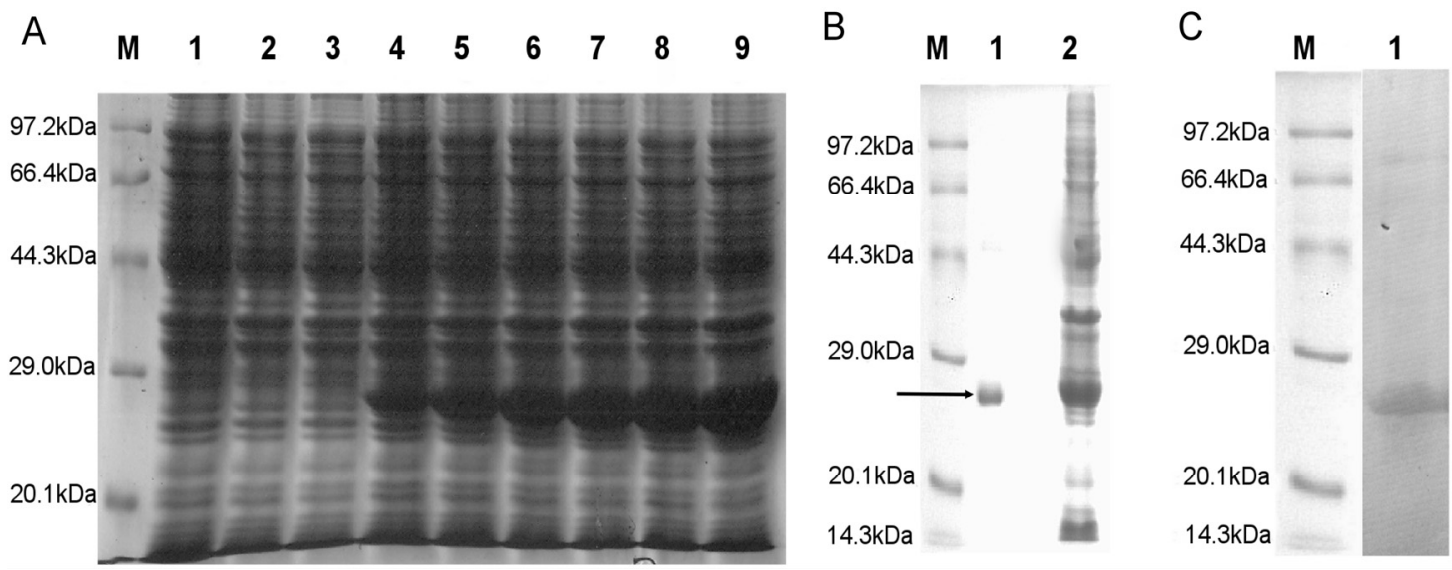

Figure 3. Specific activity of the GSTs in larval midgut of $H$. armigera subjected to sub-lethal dose of cantharidin using glutathione (GSH) and 1-chloro-2,4-dinitrobenzene (CDNB) secondary substrate. The activity of the GSTs was measured at $340 \mathrm{~nm}$ both in treated and control samples.

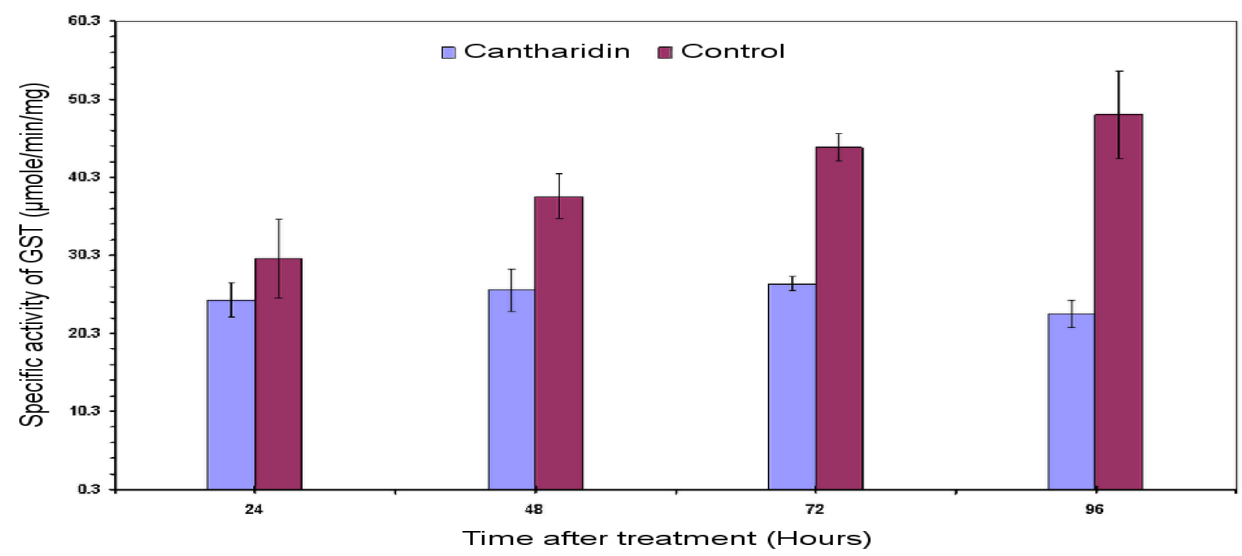

\subsection{Kinetic Properties of GSTs}

The inhibitory effects of cantharidin on the GSTs enzyme extract activity using GSH as substrate is shown in Figure 4. To find out the kind of cantharidin inhibition of the GSTs enzyme extract by cantharidin, the GSTs activity was calculated with variable concentrations of GSH. A Lineweaver-Burk plot with GSH as the variable substrate and for the type of inhibition by cantharidin is shown in Figure 4A. The Lineweaver-Burk plot revealed that cantharidin inhibited GSTs non-competitively as $V_{\max }$ lowered down, whereas Km remained unchanged with respect to GSH. 
Figure 4. Lineweaver-Burk plot of the GSTs activity in crude enzyme extract. (A) Specific activity of GSTs with and without cantharidin. IC50 value of cantharidin for the GSTs using glutathione (GSH) and 1-chloro-2,4-dinitrobenzene (CDNB) secondary substrate; (B) IC50 value was obtained using a plot of percent activities $v$ s. varying concentrations of cantharidin. S-Hexylglutathione (GTX) was used as positive control.

A

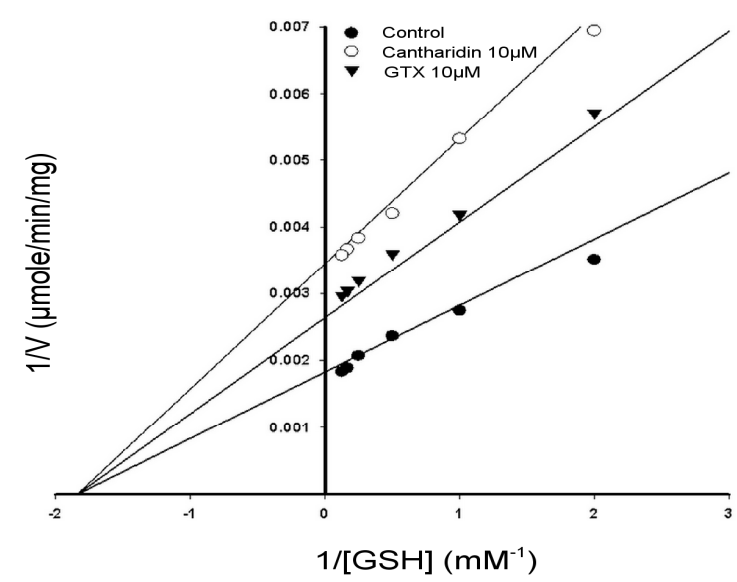

B

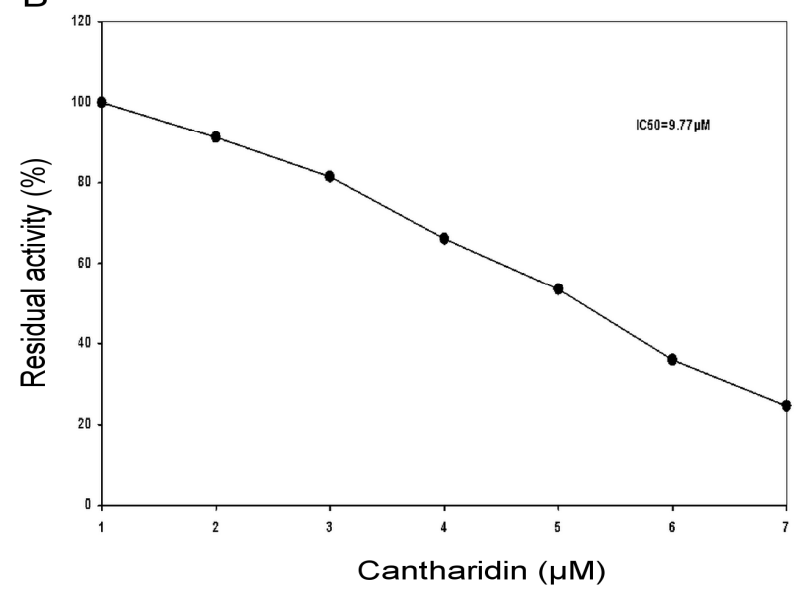

\subsection{Kinetic Properties of Purified rHaGST}

The inhibitory effects of the cantharidin on the affinity of the column purified soluble rHaGST activity using GSH as substrate is shown in Figure 5. To determine the type of inhibition of the rHaGST by cantharidin, the rHaGST activity was calculated under different concentrations of GSH. The Lineweaver-Burk plot for GSH as the variable substrate and type of inhibition is shown in Figure 5A. The Lineweaver-Burk plot revealed that cantharidin inhibited rHaGST non-competitively as $V_{\max }$ lowered, whereas $\mathrm{Km}$ remained unchanged with respect to GSH.

Figure 5. Lineweaver-Burk plot of the purified soluble rHaGST. (A) Specific activity of GSTs with and without cantharidin. IC50 value of cantharidin for GSTs using glutathione (GSH) and 1-chloro-2,4-dinitrobenzene (CDNB) secondary substrate; (B) IC50 value was obtained using a plot of percent activities vs. varying concentrations of cantharidin. $S$-Hexylglutathione (GTX) was used as positive control.

A

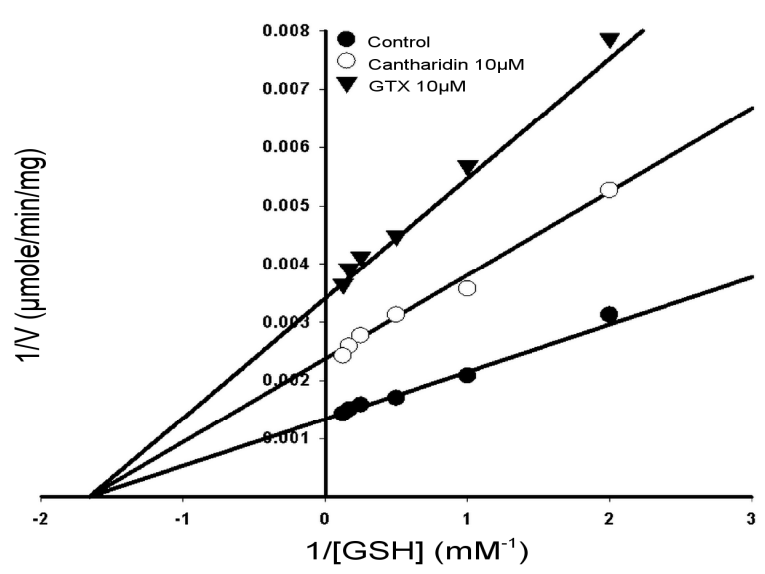

B

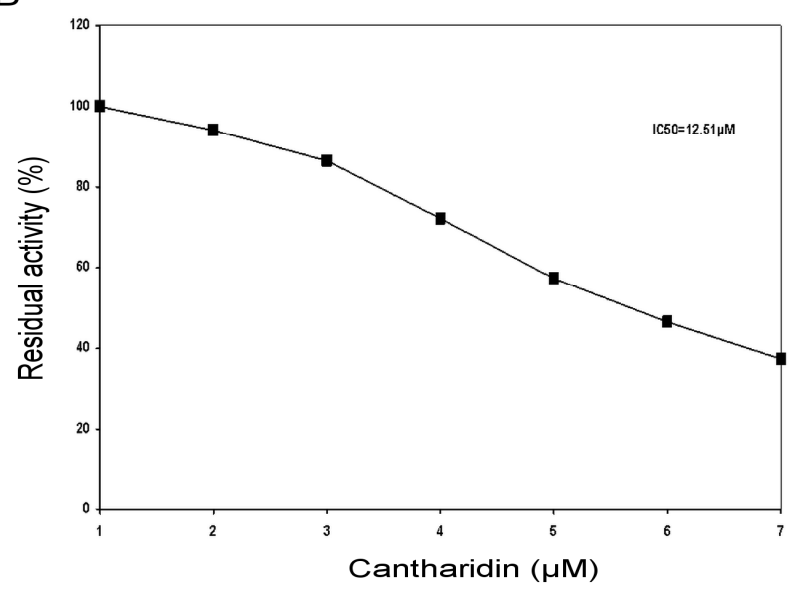




\subsection{IC50 of Cantharidin}

To calculate IC50 of cantharidin for the GSTs and the soluble purified rHaGST, variable concentrations of cantharidin were used using GSH as substrate. Results showed that cantharidin inhibited activity of the GSTs and the purified rHaGST in a dose-dependent manner with 50\% inhibitory concentration at $9.77 \mu \mathrm{M}$ (Figure 4B) and $12.5 \mu \mathrm{M}$ (Figure 5B), respectively.

\subsection{Time Course Expression Profile of the HaGST Gene by Real-Time qPCR}

Real-time qPCR was carried out to investigate the effect of cantharidin on the mRNA transcript of the HaGST based on time after treatment. Results showed that the HaGST was down-regulated at 24, 48, 72 and $96 \mathrm{~h}$ after treatment. Normalized expression results revealed that the HaGST was down regulated by 2.5, 8.3, 9.09 and 12.5 folds after 24, 48, 72 and 96 h, respectively (Figure 6).

Figure 6. The real-time q-PCR analysis of the HaGST mRNA transcript at different time intervals from 24 to $96 \mathrm{~h}$. Target gene expression was normalized by comparing $\Delta \Delta \mathrm{CT}$ to an untreated control. Error bars show standard deviation using three replications.

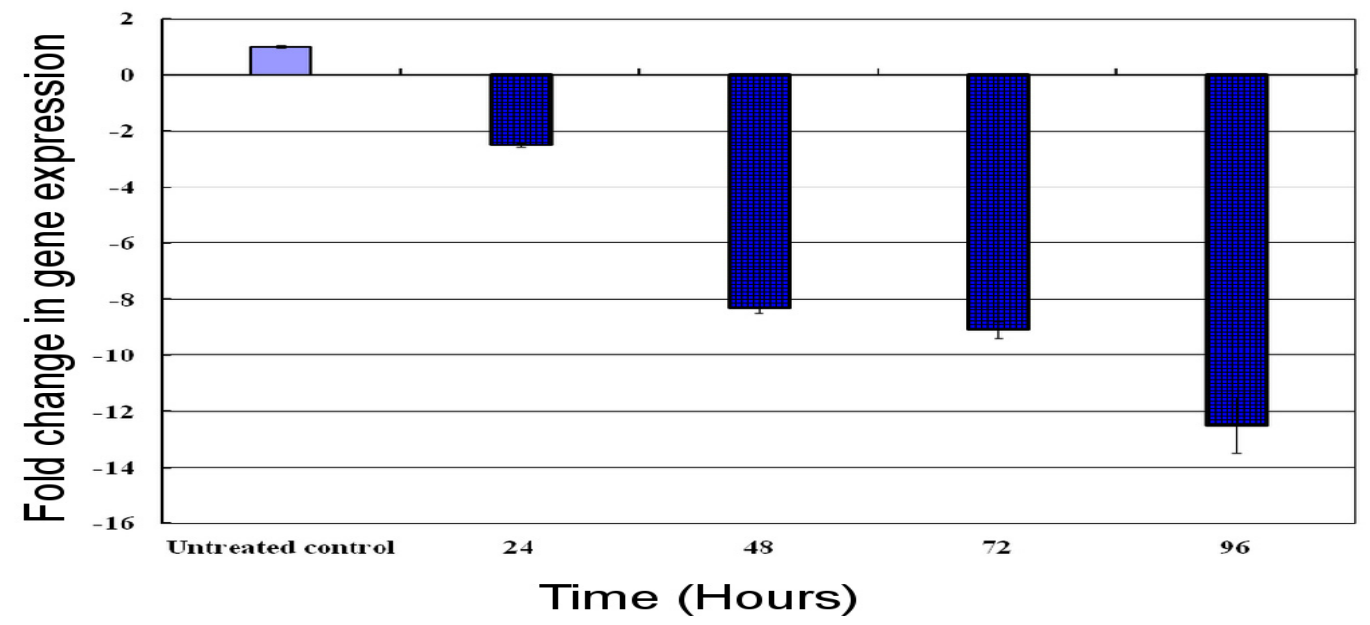

\subsection{Homology Modeling of HaGST}

In order to study the binding of cantharidin with HaGST, a better crystallographic $R$-factor (20.9\%) and higher overall sequence identity (57\%) was considered (Figure 7). We finally selected the complete crystal structure of an insect delta-class glutathione $S$-transferase from a DDT-resistant strain of the malaria vector Anopheles gambiae in complex with its inhibitor named $S$-hexylglutathione (GTX) as the template (PDB:1PN9) [22] at a resolution of $2.0 \AA$. The best model was selected with the lowest value of DOPE assessment score $(-27,127.846)$. The analysis of the Ramachandran plot showed that $97.2 \%$ (212/218) of all residues were in favored (98\%) regions, and 99.1\% (216/218) of all residues were in allowed ( $>99.8 \%$ ) regions. Only two amino acids GLU66 and ALA212 were found in the disallowed region of the Ramachandran plot. The resultant 3D structure of the HaGST is shown in Figure 8. The active site is located in a deep cleft formed at the interface of the two domains. 
Figure 7. Sequence alignment results. The target protein HaGST and template protein, IPN9. Deep green color indicates conserved residues in both the sequences. Red bands show $\alpha$ helices while blue arrows show $\beta$ sheets.

IPY9
HaGST

Figure 8. The ribbon representation of the 3-D model of the HaGST. Blue and red colors represent a chain trace from the $N$-terminus to $C$-terminus, respectively. $\alpha$ helices and $\beta$ sheets are represented by $\mathrm{H}$ and $\mathrm{B}$, respectively. The active site is located in the cleft formed at the interface of $\mathrm{H} 8, \mathrm{H} 3$ and between loops of $\mathrm{H} 2, \mathrm{~B} 3$.

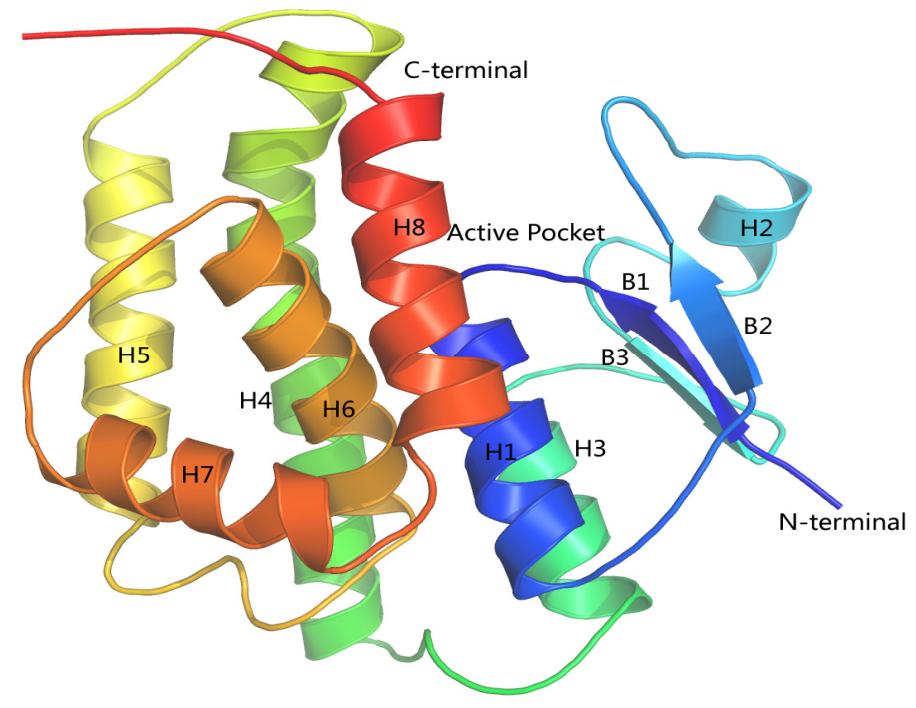

\subsection{Molecular Docking Simulations}

As shown in Figure 9 the final binding mode of the GTX-HaGST was obtained by molecular docking and superimposition (RMSD of only $0.210 \AA$ ) of the conformations of the GTX in the 1PN9 and HaGST. The O26 atom in the GTX and the NH atom of the HIS52 side chain formed hydrogen bonds having a distance of $2.2 \AA$ between atoms. The $\mathrm{NH}$ and the $\mathrm{O}$ atoms, which are derived from the VAL54 backbone, interact with the $\mathrm{O} 13$ atom and the $\mathrm{H} 8$ atom in the GTX by hydrogen bonds respectively, having distances of $1.8 \AA$ and $2.0 \AA$ between them. The NH atom of SER67 backbone also interacts with the $\mathrm{O} 5$ atom of GTX with a hydrogen bond distance of $1.9 \AA$ between atoms. The hydrogen bonds are formed between the $\mathrm{H} 2$ atom of the GTX and the $\mathrm{O}$ atom from GLU66 side chain 
whose distance is $2.4 \AA$ (Figure 10). While comparing the schematic representation of residual-ligand hydrogen bond interactions, only one interaction site in insect delta class GST, ILE52 in Anopheles gambiae may have mutated to VAL54 in Helicoverpa armigera. Although the VAL54 and the ILE52 are non-polar hydrophobic amino acids, the NH atom derived from the backbone of ILE52 only interacts with the $\mathrm{O} 13$ atom of the GTX. Based on our findings, it could be assumed that the hydrogen bond network is more stable in the GTX-HaGST 3D model complex than those in the crystal structure named 1PN9. Based on the docking work mentioned above, the accurate binding mode of the HaGST 3D model with the cantharidin was obtained as shown in Figure 11.

Figure 9. The binding model of GTX with the HaGST. Red dotted lines show hydrogen bonding among the corresponding atoms of amino acid residues of the active site and GTX.

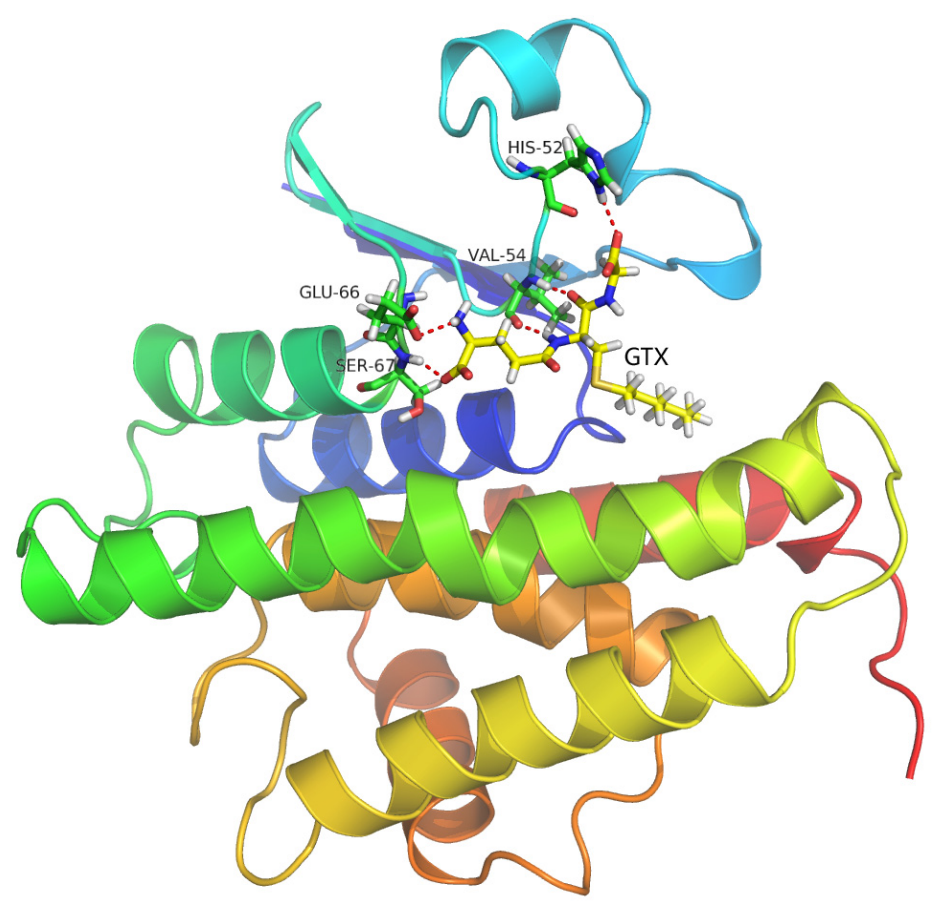

Figure 10. The interaction diagram of the insect delta-class HaGST from Helicoverpa armigera with its inhibitor, GTX.

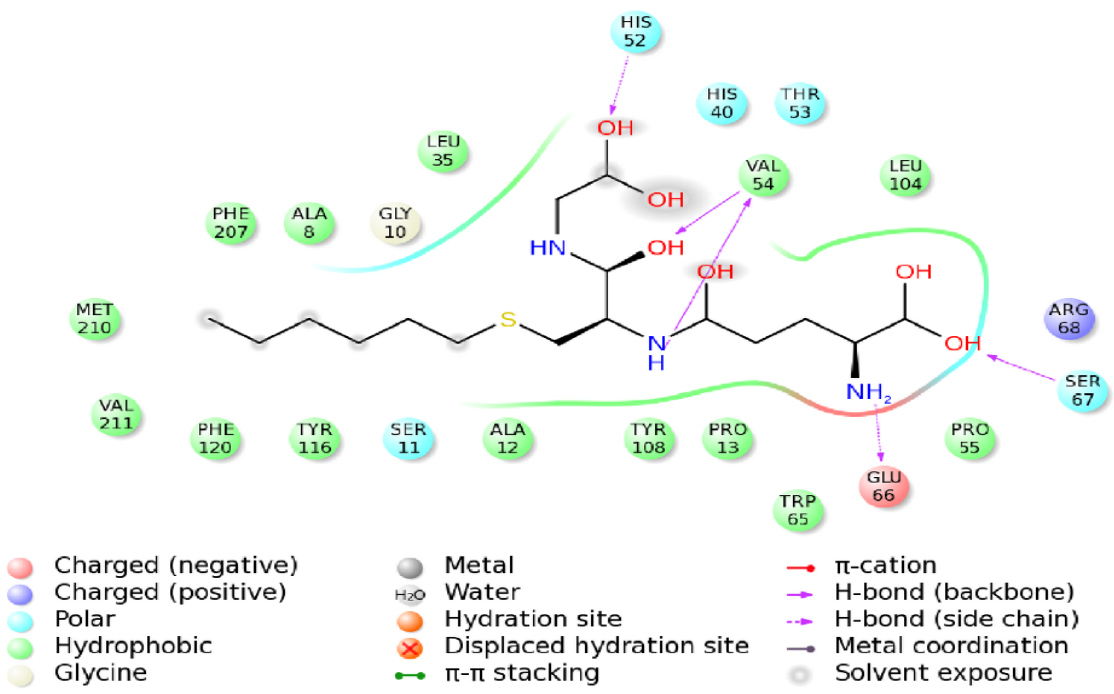


Figure 11. Binding mode of the cantharidin-HaGST complex. Red dotted lines show hydrogen bonding between the amino acid residues of the active site and atoms of cantharidin. The O atom of GLY10 and NH atom of ALA12 interact with the cantharidin $\mathrm{O} 3$ atom, simultaneously by hydrogen bonding. The $\mathrm{OH}$ atom of TRY116 also interacts with the $\mathrm{O} 3$ atom of cantharidin. $\mathrm{A} \mathrm{OH}$ atom of TRY108 forming a hydrogen bond with O1 of cantharidin plays an important role in binding affinity based on its lowest inter-atomic distance.

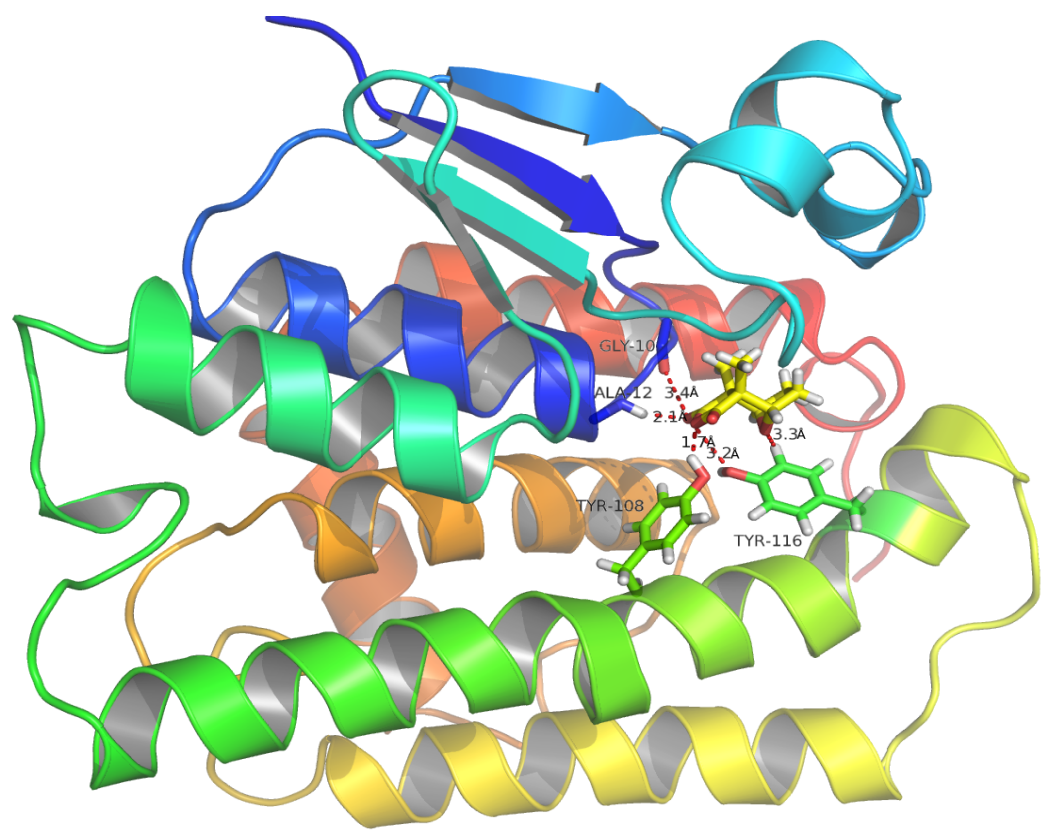

Figure 12. The Interaction diagram of the delta class HaGST with cantharidin. ALA12 and TRY108 are mainly responsible for making hydrogen bonds with the $\mathrm{O}$ atoms of cantharidin.

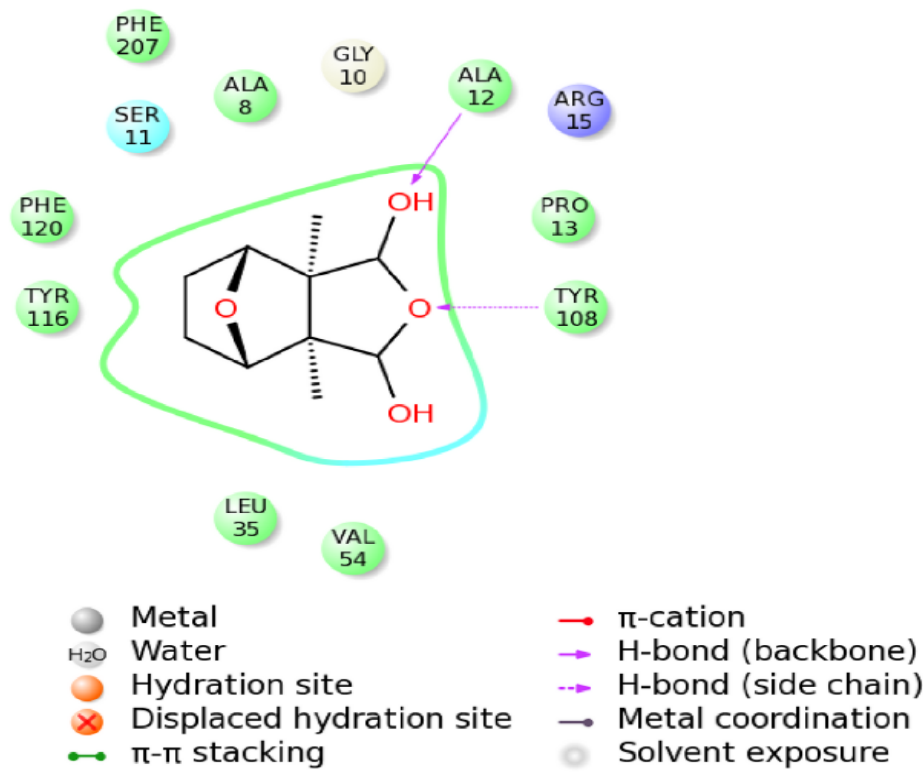

The schematic representation of residue-ligand interactions for cantharidin is shown in Figure 12. The cantharidin docks inside the active site formed by amino acid residues TYR116, PHE120, SER11, 
ALA8, GLY10, ALA12, ARG15, PRO13, TYR108, LEU35, VAL54. The O atom of GLY10 and the $\mathrm{NH}$ atom of ALA12 which are both derived from the backbone of the HaGST 3D model simultaneously interact with the $\mathrm{O} 3$ atom of the cantharidin by hydrogen bonds, whose distances are $3.4 \AA$ and $2.1 \AA$, respectively. The $\mathrm{OH}$ atom from the side chain of TYR116 also interacts with the O3 atom of the cantharidin by hydrogen bonds. The hydrogen bonds are formed between the $\mathrm{OH}$ atom of TYR108 and the $\mathrm{O} 1$ atom of the cantharidin which are only1.7 $\AA$ apart. The smaller distance of $1.7 \AA$ between the $\mathrm{OH}$ atom of TYR 108 and the $\mathrm{O} 1$ atom of the cantharidin may have a profound impact on their binding affinity. The hydrogen bond network occupying the active site of HaGST allows the formation of the stable complex with cantharidin.

\subsection{Binding Energy Calculations}

As shown in Table 1, the calculated binding energy delta G (DG) indicates that cantharidin has a higher binding affinity than the GTX.

Table 1. Delta G values of compounds, GTX and cantharidin against the HaGST 3D model. A ChemScore function was applied to measure affinity data by ranking according to ChemScore delta value.

\begin{tabular}{cccccccc}
\hline Molecule & Score & DG & S (hbond) & S (lipo) & H (rot) & DE (clash) & DE (int) \\
\hline GTX & 16.76 & -19.65 & 3.87 & 142.65 & 6.04 & 0.10 & 2.79 \\
Cantharidin & 21.58 & -21.86 & 1.80 & 88.77 & 0.00 & 0.28 & 0.00 \\
\hline
\end{tabular}

In our current research we have used GST as a molecular target of cantharidin since GSTs plays an important role in defense against plant allelochemicals [6] as well as insecticides [7].

Earlier studies have suggested the increased level of GSTs as one of the major reasons for the development of resistance using metabolic detoxification of insecticides. Many researchers have documented the development of insecticide resistance caused by increased levels of GSTs especially in diamondback moth (DBM) and H. armigera which are phylogenetically related. In one report, indiscriminate use of insecticides, multiple generation of DBM per annum and year round availability of host crops have been mentioned as reasons for development of resistance in this pest to all kinds of insecticides [23,24]. There is a clear correlation between resistance and level of GSTs in insects. Likewise, there is higher activity of GST in the DBM-R population by a 3 to 4 fold increase in enzyme activity over susceptible strains of Plutella xylostella [25]. Similarly, a 1.5 to 2 fold increase in parathione selected DBM was observed [26]. Higher activity of GSTs in pyrethroid resistant strain has established that GST plays an important role as a detoxifying mechanism in DBM [27]. There are earlier reports of resistance in H. armigera to synthetic and nonsynthetic pyrethroid insecticides in China, with resistance to deltamethrin, cyhalothrin, fenpropathrin, esfenvalerate, cyfluthrin and methomyl ranging between 10 and 50-fold [28]. GST could provide passive protection by binding pyrethroid molecules in a sequestration mechanism in resistant field strains of $H$. armigera [29]. Detoxifying GSTs are a family of enzymes that catalyze the conjugation of glutathione with electrophilic substrates including insecticides [30]. The GSTs are involved in $O$-dealkylation or dearylation of OPs [31]. High frequencies of profenofos resistance were moderately correlated with GST activity toward 1-chloro-2,4-dinitrobenzene in larvae of $H$. virescens that were collected in 
Louisiana cotton fields during the 1995 cotton growing season [32]. A recent study suggests that GSTs act as an antioxidant-defense agent and confer pyrethroid resistance in Nilaparvata lugens and possibly in other insects [33]. Enhanced activities of GSTs that confer insecticide resistance result from both quantitative and qualitative alterations in gene expression. First, there is evidence for over-expression of one or more GST isoforms in resistant insects. For example, the highest activity found in an insecticide-resistant strain of $M$. domestica is correlated with a high level of GST1 transcript [12].

Our investigations revealed that cantharidin is an effective inhibitor of the GSTs and the HaGST in the midgut of $H$. armigera with IC50 of 9.77 and $12.5 \mu \mathrm{M}$, respectively. The low value of IC50 in vivo suggests that it may be a general inhibitor of GSTs. Enzyme kinetics studies were carried out to detect the inhibitory mechanism of GSTs in enzyme extract and soluble purified rHaGST by cantharidin with respect to GSH. Results revealed that cantharidin was non-competitive inhibitor of the GSTs and the HaGST with respect to GSH, suggesting that cantharidin binding to GSTs may have caused conformational changes consequently leading to the enzyme inactivation. Furthermore, cantharidin has the potential to bind to GSTs through hydrogen a bond causing steric obstruction leading to inactivation of catalytic activity.

Homology modeling and molecular docking simulations were employed to rationalize our results more precisely. Our docking results confirmed putative binding of cantharidin to the catalytic active site residues, ALA12 and TRY108, resultantly causing conformational changes that lead to the inactivation of enzyme catalytic activity.

\section{Experimental Section}

\subsection{Insects}

Helicoverpa armigera larvae were procured from Henan Jiyuan Baiyun Industry Co., Ltd. China and reared on artificial diet [34] until F1 were available for use in the experiments. Groups of 24 larvae were placed into 24 chamber plastic boxes obtained from the company. The boxes were placed in an incubator at $27+1{ }^{\circ} \mathrm{C}$ and $40 \%$ to $50 \% \mathrm{RH}$ with a $12 \mathrm{~h}$ photoperiod.

\subsection{Bioassay}

Diet incorporation bioassay was used to determine the toxicity of cantharidin. Batches of healthy homogeneous third-instar larvae were selected for bioassay. A homogeneous group comprising 24 larvae per replication was subjected to bioassay. The bioassay experiment was replicated thrice. Cantharidin dissolved in acetone was added to the semisolid artificial diet at the rate of $250 \mu \mathrm{g} \mathrm{g}^{-1}$ and mixed well. Acetone was allowed to evaporate for $1 \mathrm{~h}$ before allowing insects to feed. The larvae were starved for $8 \mathrm{~h}$ before their introduction to treated diet. One larva of third-instar was introduced to each cell of the 24-cell plastic bioassay tray. The mortality data were recorded at 12, 24, 48 and $72 \mathrm{~h}$.

\subsection{Larval Treatment}

Cantharidin used in the experiment was extracted in the laboratory. The third-instar larvae were selected for this study. The insects were starved for $8 \mathrm{~h}$ before their introduction to the cantharidin-treated artificial diet containing $25 \mu \mathrm{g} \mathrm{g}{ }^{-1}$ cantharidin. Afterward, larvae were collected at 
an interval of 24, 48, 72 and $96 \mathrm{~h}$. The collected larvae were flash frozen in liquid nitrogen for storage at $-80{ }^{\circ} \mathrm{C}$ and subsequently used for extraction of enzyme extract and total RNA for synthesis of cDNAs.

\subsection{Total RNA Preparation and Synthesis of cDNAs Template for Real-Time qPCR}

A total of $10 \times 3$ larvae per time interval (10 larvae per replication), treated as mentioned above were used for extraction of total RNA. At first midguts were dissected from the larvae stored at $-80{ }^{\circ} \mathrm{C}$ and homogenized using liquid nitrogen before addition of RNAiso Plus (TaKaRa, Dalian, China). RNA was extracted under the guidelines of the manufacturer's instructions. The quality of the RNA samples was examined by running on $1 \%(w / v)$ agarose gel. DNA contamination was removed by DNaseI (Fermentas, Beijing, China). The cDNAs were synthesized by reverse transcription using RevertAid $^{\mathrm{TM}}$ Reverse Transcriptase (Fermentas, Beijing, China) in a $20 \mu \mathrm{L}$ reaction containing $5 \mu \mathrm{L}$ total RNA having $1 \mu \mathrm{g}$ RNA, oligo $(\mathrm{dT})_{18}$ primer $1 \mu \mathrm{L}, 5 \times$ Reaction Buffer $4 \mu \mathrm{L}, 10 \mathrm{mM}$ dNTP Mix $2 \mu \mathrm{L}$ and RevertAid ${ }^{\mathrm{TM}} \mathrm{M}-\mathrm{MuLV}$ Reverse Transcriptase $\left(200 \mathrm{U}^{-1}\right) 1 \mu \mathrm{L}$. The reaction mixture was incubated for $60 \mathrm{~min}$ at $42{ }^{\circ} \mathrm{C}$. The reaction was terminated by heating at $70{ }^{\circ} \mathrm{C}$ for $10 \mathrm{~min}$. The product of the reverse transcription reaction was stored at $-80{ }^{\circ} \mathrm{C}$.

\subsection{Cloning of Glutathione S-Transferase Gene from $\mathrm{H}$. armigera}

Glutathione $S$-transferase (GenBank accession no. EF033109) was amplified from cDNA by polymerase chain reaction (PCR) using a pair of sense and antisense primers, respectively (Table 2). The BamHI restriction site was incorporated to sense primer, whereas HindIII restriction site was incorporated to antisense primer for double restriction digestion reaction. The amplification reaction was performed by the PCR program: first step denaturation for $3 \mathrm{~min}$ at $95{ }^{\circ} \mathrm{C}$ followed by 34 cycles of $95{ }^{\circ} \mathrm{C}$ for $30 \mathrm{~s}, 55^{\circ} \mathrm{C} 30 \mathrm{~s}, 72{ }^{\circ} \mathrm{C}$ for $1 \mathrm{~min}$ and final extension of $5 \mathrm{~min}$ at $72{ }^{\circ} \mathrm{C}$. The PCR product was run on $1 \%(w / v)$ agarose gel and visualized by ethidium bromide using the BioRad imaging system. Target gene amplified product was gel purified by a gel extraction kit (Biomiga, San Diego, CA, USA). Gel purified PCR product was then ligated to pMD-19T vector (TaKaRa, Dalian, China) and transformed into Escherichia coli DH5a. The transformants were selected on LB agar plates containing $50 \mu \mathrm{g} \mathrm{mL}^{-1}$ kanamycin after overnight incubation at $37^{\circ} \mathrm{C}$. The resultant PCR clones were sequenced by Shanghai Sunny Biotech, Shanghai, China.

Table 2. Oligonucleotide primer sequences for the reverse transcription and the real-time qPCR used in this study.

\begin{tabular}{ccccc}
\hline Name (bp) & Sequence (5-3) & Usage & $\boldsymbol{T}_{\mathbf{m}}{ }^{\mathbf{a}}$ & $\begin{array}{c}\text { Corresponding } \\
\text { cDNA region }\end{array}$ \\
\hline HaGST-F (29) & CGGATCCATGTCCTTAGACTTGTATTACG & RT & 59.2 & $43-705$ \\
HaGST-R (30) & CGAAGCTTTTACAATTCAGTTTTAGCTTTT & RT & 56.6 & \\
HaGST-Fq (19) & ACGCTTTACCCAAGATTTG & Real-time qPCR & 60 & $316-430$ \\
HaGST-Rq (19) & GGAATGTGTTGAGGAAGTG & Real-time qPCR & 60 & \\
HaBA-Fq (18) & GTATTGCTGACCGTATGC & Real-time qPCR & 59.7 & $11-\mathrm{s} 152$ \\
HaBA-Rq (18) & ATCTGTTGGAAGGTGGAG & Real-time qPCR & 60 & \\
\hline
\end{tabular}

${ }^{\text {a }}$ Melting temperature $\left(T_{\mathrm{m}}\right)$ of the primers was calculated by Beacon Designer 7 software. 


\subsection{Construction of Recombinant Expression Plasmid}

The pMD19T-HaGST was subjected to double restriction digestion by BamHI and HindIII. The digested fragments were gel purified and ligated into the prokaryotic expression vector, pET-28a (Novagen, Darmstadt, Germany) using TaKaRa quick ligation kit to secure the recombinant plasmid, rHaGST. The ligation reaction was transformed into BL-21 (DE-3) competent cells. The transformed B1-21 cells were cultured in LB media containing kanamycin $\left(50 \mu \mathrm{g} \mathrm{mL}{ }^{-1}\right)$ at $37{ }^{\circ} \mathrm{C}$ with $220 \mathrm{rpm}$ shaking until the absorbance at $\mathrm{OD}_{600}$ reached $0.5 \mathrm{~nm}$, then isopropyl- $\beta$-D-thiogalactopyranoside (IPTG) was added to the culture in final concentration of $1 \mathrm{mM}$ at $30{ }^{\circ} \mathrm{C}$ for expression of recombinant protein.

\subsection{SDS-PAGE Analysis of Recombinant Protein and Immunoblotting}

The expressed recombinant protein of $29.81 \mathrm{kDa}$ was confirmed and visualized by $12 \%$ SDS-PAGE using a standard protein marker (TaKaRa, Dalian, China). After running the recombinant protein on $12 \%$ SDS-PAGE, the gel was subjected to Coomassie brilliant blue R250 staining and proteins were transferred to a polyvinylidene fluoride membrane (PVDF). Immunoblotting was done [35] with 6-His monoclonal primary antibody and peroxidase-conjugated goat anti-mouse IgG secondary antibody.

\subsection{Prokaryotic Expression and Purification of the Soluble Recombinant Protein, rHaGST}

The E. coli strain Bl-21 (DE-3) cells with the rHaGST were grown at $37{ }^{\circ} \mathrm{C}$ in $50 \mathrm{~mL} \mathrm{LB}$ media containing $50 \mu \mathrm{g} \mathrm{mL}^{-1}$ kanamycin until the $\mathrm{OD}_{600}$ reached 1 . The media was then added $0.5 \mathrm{mM}$ IPTG and cells were grown at $28^{\circ} \mathrm{C}$ for $6 \mathrm{~h}$ with shaking at $200 \mathrm{rpm}$. The cells were harvested at 10,000 rpm for one min. The resultant pellet was washed with sterile water three times and finally mixed with the binding buffer containing $20 \mathrm{mM}$ imidazol in equilibration buffer. Lysozyme was added to the mixture at the rate of $1 \mathrm{mg} \mathrm{mL}^{-1}$. After incubation for $30 \mathrm{~min}$ on ice, cells were lysed by gentle vortexing. The lysate was subjected to centrifugation at $12,000 \mathrm{rpm}$ for $10 \mathrm{~min}$ to remove the cellular debris. The supernatant was passed through a $0.45 \mathrm{nM}$ syringe filter for removal of any remaining debris. The protein extract obtained was passed through a $\mathrm{Ni}^{2+}$-nitrilotriacetate (NTA) chromatographic column. The column was washed with equilibration buffer containing, $300 \mathrm{mM} \mathrm{NaCl}, 50 \mathrm{mM}$ sodium phosphate buffer, $10 \mathrm{mM}$ imidazol and $0.01 \mathrm{M}$ Tris-Cl $(\mathrm{pH} \mathrm{8.0)}$. Protein was eluted with a linear imidazole gradient of 50,100, 150 and $200 \mathrm{mM}$. The eluted protein was desalted using a dialysis membrane against $50 \mathrm{mM}$ sodium phosphate buffer, $\mathrm{pH} 7.2$ for $24 \mathrm{~h}$ at $4{ }^{\circ} \mathrm{C}$.

\subsection{Enzyme Extract Preparation}

A total of $10 \times 3$ larvae per time interval (10 larvae per replication), treated as mentioned above were used for enzyme extraction. The midguts dissected from the larvae were washed with $1 \times$ phosphate buffer and homogenized in $0.1 \mathrm{M}$ potassium phosphate buffer, $\mathrm{pH} 6.5$ on ice using a glass homogenizer. The homogenates were centrifuged at $10,000 \mathrm{~g}$ for $15 \mathrm{~min}$ at $4{ }^{\circ} \mathrm{C}$. The supernatants were used as an enzyme extract solution. 


\subsection{GST Activity Determination Assay}

Glutathion $S$-transferase activity was determined by an earlier method with little modifications [36]. Ten microliters of ten-times diluted enzyme extract solution was added to a total volume of $200 \mu \mathrm{L}$ in microplate wells. The reaction mixture was incubated with $10 \mathrm{mM}$ glutathione at $25{ }^{\circ} \mathrm{C}$ for $10 \mathrm{~min}$ and added $10 \mu \mathrm{L} \quad 10 \mathrm{mM}$ 1-chloro-2,4-dinitrobenzene (CDNB). Enzyme activity was measured spectrophotometrically at $340 \mathrm{~nm}$ using a TECAN ${ }^{\mathrm{TM}}$ Infinite $^{\circledR} 200$ PRO multimode micro-plate reader. The enzyme activity was determined using the extinction coefficient of $9.6 \mathrm{mM}^{-1} \mathrm{~cm}^{-1}$ for CDNB.

\subsection{Kinetic Properties of GST}

The enzyme extract solution was prepared as mentioned above. Ten microliters of $10 \mu \mathrm{M}$ cantharidin dissolved in acetone was added to the reaction mixture as an inhibitor. $S$-Hexylglutathione (GTX) in a concentration of $10 \mu \mathrm{M}$ was used as a positive control. The reaction was started by the addition of $10 \mathrm{mM}$ glutathione and the reaction mixture was incubated at $25{ }^{\circ} \mathrm{C}$ for 10 min and finally added $10 \mu \mathrm{L}$ of $10 \mathrm{mM}$ CDNB. The enzyme activity was measured spectrophotometrically at $340 \mathrm{~nm}$ using a TECAN ${ }^{\mathrm{TM}}$ Infinite $^{\circledR} 200$ PRO multimode micro-plate reader. The enzyme activity was determined using the extinction coefficient of $9.6 \mathrm{mM}^{-1} \mathrm{~cm}^{-1}$ for CDNB.

\subsection{Kinetic Properties of Purified Soluble rHaGST}

In this assay the purified rHaGST as mentioned above was used as the enzyme source. Ten microliters of $10 \times$ diluted purified GST enzyme solution was added to the reaction mixture. Ten microliters of $10 \mu \mathrm{M}$ cantharidin dissolved in acetone was added to the reaction mixture as an inhibitor. S-Hexylglutathione (GTX) in a concentration of $10 \mu \mathrm{M}$ was used as a positive control. The reaction was started by the addition of $10 \mathrm{mM}$ glutathione and the reaction mixture was incubated at $25{ }^{\circ} \mathrm{C}$ for $10 \mathrm{~min}$ and added $10 \mu \mathrm{L} 10 \mathrm{mM}$ CDNB. Enzyme activity was measured spectrophotometrically at $340 \mathrm{~nm}$ using the TECAN ${ }^{\mathrm{TM}}$ Infinite ${ }^{\circledR} 200$ PRO multimode micro-plate reader. The enzyme activity was determined using the extinction coefficient of $9.6 \mathrm{mM}^{-1} \mathrm{~cm}^{-1}$ for CDNB. The enzyme kinetics module of the SigmaPlot computer package was used to analyze enzyme kinetics data (SigmaPlot, Systat Software, San Jose, CA. USA).

\subsection{Determination of IC50}

To calculate the concentration of inhibitor that inhibits $50 \%$ activity of enzyme (IC50), variable concentration of cantharidin dissolved in acetone were added to the mixture containing $170 \mu \mathrm{L}$ GST buffer, $10 \mu \mathrm{L}$ enzyme extract and $10 \mu \mathrm{L}$ of $10 \mathrm{mM} \mathrm{GSH}$ solution at $25^{\circ} \mathrm{C}$. No inhibitor was added to the control. The inhibition reaction was carried out at $25^{\circ} \mathrm{C}$. The value of IC50 was calculated by percent inhibitory activity $v s$. concentration of inhibitor using Microsoft Excel 2003.

\subsection{Real-Time qPCR Analysis of Gene Expression}

The real-time qPCR was performed by a BioRad iQ ${ }^{\mathrm{TM}} 5$ cycler. The real-time qPCR reaction was carried out in PCR strips. SYBR Green was used to detect an amplification signal. The reaction 
mixture consisted of $1 \mu \mathrm{L} 10 \times$ diluted cDNA templates, $0.5 \mu \mathrm{L}$ of $10 \mu \mathrm{M}$ forward/reverse primers and Maxima $^{\mathrm{TM}}$ SYBR Green/ROX qPCR Master Mix (Fermentas, Beijing, China) in a final volume of $25 \mu \mathrm{L}$. Forward and reverse primers were used as mentioned above. The real time PCR condition used: initial denaturing at $95{ }^{\circ} \mathrm{C}$ for $30 \mathrm{~s}$, forty cycles of $95{ }^{\circ} \mathrm{C}$ for $10 \mathrm{~s}, 60{ }^{\circ} \mathrm{C}$ for $30 \mathrm{~s}$ and $72{ }^{\circ} \mathrm{C}$ for $30 \mathrm{~s}$. The real time data were acquired at $72{ }^{\circ} \mathrm{C}$. Three replicate for each sample were used for real time PCR analysis. The quantification of the relative transcript levels was performed using the comparative CT method. The expression ratio $(R)$ was calculated as recommended by the manufacturer and corresponds to $2^{-\Delta \Delta \mathrm{CT}}$, where:

$$
\text { Ratio }=\frac{\left(E_{\text {target }}\right)^{\Delta C_{\mathrm{r}} \text { target (calibrator - test) }}}{\left(E_{\text {reference }}\right)^{\Delta C \mathrm{~T} \text { target (calibrator - test) }}}
$$

Relative quantification relies on the comparison between expression of a target gene versus a reference gene (Helicoverpa armigera $\beta$-actin) and the expression of the same gene in the target sample versus the reference sample [37].

\subsection{Homology Modeling of HaGST}

In this study, we used glutathione $S$-transferase of Helicoverpa armigera (HaGST) (ABK40535) obtained from the GenBank database [21] having 220 amino acid residues as a model sequence. All Homology Modeling computations were performed using the Modeller 9.10 [38] on a Linux High performance workstation based on 2 Intel Xeon 5680 processors (Super Micro Computer Inc., San Jose, CA, USA).

Using our model HaGST sequence as a probe, the PDB95 database was searched for non-redundant PDB sequences to select the most appropriate template for our query sequence. In order to visualize differences among 12 similar structures selected at 95\% sequence identity as the candidate template, we compared all of the structures in the dendrogram, which can generate the weighted pair-group average clustering based on a distance matrix. The best template was picked according to the crystallographic $R$-factor and overall sequence identity. The sequence alignment between the HaGST sequence and the best template was generated by Align2D and also identified by ClustalX with the Blosum scoring function [39]. The best alignment was selected according to both the alignment score and the reciprocal positions of the conserved residues, especially those in or close to the GTX-binding sites of the template.

Once the target template alignment was constructed, it calculated 100 3D models of the target automatically by the automodel of Modeller using the optimization and refinement protocol. Each model was first optimized with the variable target function method (VTFM) with conjugate gradients (CG), and was then refined using molecular dynamics (MD) with simulated annealing (SA). We also used the loop model class in Modeller to refine the conformation of the loop between residues. To measure the relative stability of the protein conformation, GA341 and Discrete Optimized Protein Energy (DOPE) scores were employed and credible structure of HaGST was selected based on the lowest DOPE energy. MolProbity was used to generate the Protein Main-Chain dihedral Ramachandran map to identify the rationality of the stereochemical for the structure [40]. 


\subsection{Molecular Docking Simulations}

All the simulations and docking work was performed using the software, GOLD 5.1 [41]. GTX is bound tightly inside the active-site pocket formed by residues Leu6, Ser9, Ala10, Pro11, Leu33, Met34, His38, His50, Ile52, Glu64, Ser65, Arg66, Tyr105, Phe108, Tyr113, Ile116, Phe117, Phe203 and Phe207 as observed from the crystal structure. This pocket was selected as a binding site for cantharidin, so we aligned the 3D model of HaGST to the crystal structure by the superimposition in pymol 1.3r1 edu [42], saved the coordinates of the 3D model of HaGST, then used the coordinates of the CA2 atom in GTX to define a centroid close to the center of the active site with the radius of $10 \AA$. In order to adopt the best sets of docking parameters and obtain the reliability of the docking results, the GTX was first docked into the binding pocket. The chemical structure of the cantharidin was derived from PubChem [43] and directly used the structure of GTX from 1PN9. Mercury 3.0 software [44] was used to add hydrogen atoms and the coordinates were saved as MOL2 files. Hydrogen atoms were added to the 3D model structure of HaGST and correct ionization and tautomeric states of residues such as Asp, Glu and His were defined, allowing serine, threonine and tyrosine hydroxyl groups, as well as lysine $\mathrm{NH}^{3+}$ groups to rotate during docking. All torsion angles in each ligand were allowed to rotate freely. An accurate GTX-GST complex possessing the smallest root-mean-square deviation of the docked conformation of GTX from its conformation in the crystal structure named 1PN9 was obtained first by docking using Goldscore and then by Chemscore after tuning parameters of Gold software several times. Similar docking parameters were adopted for cantharidin and GTX.

\subsection{Binding Energy Calculations}

In order to compare the binding affinity between the cantharidin and GTX with the HaGST model, a ChemScore function was applied to measure the affinity data by a ranking made according to delta value. ChemScore estimates of the total free energy change that occurs on ligand binding were estimated:

$$
\Delta G_{\text {binding }}=\Delta G_{\mathrm{O}}+\Delta G_{\text {hbond }}+\Delta G_{\text {metal }}+\Delta G_{\text {lipo }}+\Delta G_{\text {rot }}
$$

\section{Conclusions}

In brief, the results from our investigations revealed that the cantharidin is a potent inhibitor of the GSTs in vivo and the HaGST in vitro. We therefore suggest the use of cantharidin based bio-insecticides directly or as a synergist where insecticide resistance is related to the over expression of GSTs.

\section{Acknowledgments}

We sincerely appreciate Schrock, J.R. (Emporia State University, USA) for revising the manuscript. This study was supported by the Special Fund for the Public Interest (Agriculture) (200903052) by The Ministry of Science and Technology, The Ministry of Agriculture, China. The NSFC grants (31270691, 31170609) and the "13115" Sci-Tech Innovation Project of Shaanxi Province (2007ZDKG-14). 


\section{Conflict of Interest}

The authors declare no conflict of interest.

\section{References}

1. Hayes, J.D.; Pulford, D.J. The glutathione $S$-transferase supergene family-regulation of GST and the contribution of isozymes to cancer chemoprotection and drug resistance. Crit. Rev. Biochem. Mol. Biol. 1995, 30, 445-600.

2. Habig, W.H.; Pabst, M.J.; Jakoby, W.B. Glutathione S-transferases. J. Biol. Chem. 1974, 249, $7130-7141$.

3. Grant, D.F.; Dietze, E.C.; Hammock, B.D. Glutathione $S$-transferase isozymes in Aedes aegypti: Purification, characterization and isozyme specific regulation. Insect Biochem. 1991, 21, 421-433.

4. Huang, H.S.; Hu, N.T.; Yao, Y.E.; Wu, C.Y.; Chiang, S.W.; Sun, C.N. Molecular cloning and heterologous expression of glutathione $S$-transferase involved in insecticide resistance from the diamondback moth, Plutella xylostella. Insect Biochem. Mol. Biol. 1998, 28, 651-658.

5. Armes, N.J.; Jadhav, D.R.; Bond, G.S.; King, A.B.S. Insecticide resistance in Helicoverpa armigera in South India. Pestic. Sci. 1992, 34, 355-364.

6. Yu, S.J. Molecular Aspects of Insect-Plant Association; Brattsten, L.B., Ahmad, S., Eds.; Plenum: New York, NY, USA, 1986; p. 153.

7. Motoyama, N.; Dauterman, W.C. Glutathione $S$-transferases: Their role in the metabolism of organophosphorus insecticides. Rev. Biochem. Toxicol. 1980, 20, 49-70.

8. Motoyama, N.; Dauterman, W.C. Inter-strain comparison of glutathione dependent reactions in susceptible and resistant houseflies. Pestic. Biochem. Physiol. 1975, 5, 489-493.

9. Clark, A.G.; Shamaan, N.A.; Dauterman, W.C.; Hayaoka, T. Characterization of multiple glutathione transferases from the housefly, Musca domestica. Pestic. Biochem. Physiol. 1984, 22, 51-59.

10. Hemingway, J.; Malcolm, C.A.; Kissoon, K.E.; Boddington, R.G.; Curtis, C.F.; Hill, N. The biochemistry of insecticide resistance in Anopheles sacharovi: Comparative studies with a range of insecticide susceptible and resistance Anopheles and Culex species. Pestic. Biochem. Physiol. 1985, 24, 68-71.

11. Grant, D.F.; Matsumura, F. Glutathione $S$-transferase 1 and 2 in susceptible and insecticide resistant Aedes aegypti. Pestic. Biochem. Physiol. 1989, 33, 132-140.

12. Fournier, D.; Bride, J.M.; Poire, M.; Berge, J.B.; Plapp, F.W. Insect glutathione $S$-transferases: Biochemical characteristics of the major forms from houseflies susceptible and resistant to insecticides. J. Biol. Chem. 1992, 267, 1840-1845.

13. Legadic, L.; Cuany, A.; Berge, J.B.; Echaubard, M. Purification and partial characterization of glutathione $S$-transferases from insecticide resistant and lindane-induced susceptible Spodoptera littoralis (Boisd.) larvae. Insect Biochem. Mol. Biol. 1993, 23, 467-474.

14. Zibaee, A.; Jalali, S.J.; Alinia, F.; Ghadamyari, M. Diazinon resistance in different selected strains of Chilo suppressalis Walker (Lepidoptera: Pyralidae), rice striped stem borer, in the north of Iran. J. Econ. Entomol. 2008, 102, 1189-1196. 
15. Wang, G.S. Medical uses of Mylabris in ancient China and recent studies. J. Ethnoparmacol. 1989, 26, 147-162.

16. Oaks, W.W.; diTunno, J.F.; Magnam, T.; Levy, H.A.; Mills, L.C. Cantharidin Poisoning. Arch. Intern. Med. 1960, 105, 574-582.

17. Robiquet, P.J. Expériences sur les cantharides. Ann. Chim. 1810, 76, 302-322.

18. Cui, F.L.; Li, X.; Ma, Z.Q.; Zhang, Y.L. Safety evaluation of animal-origin pesticide cantharidin against some non-target organisms. J. Environ. Entomol. 2009, 31, 143-149.

19. Zhang, Y.L.; Zhou, Y.; Zhang, Z.Y. Effect of cantharidin on the midgut of oriental armyworm (Methimna. seperata) and diamond moth Plutella xylostella. Acta Entomol. Sin. 2003, 46, 272-276.

20. Ma, Y.; Liu, R.R.; Ma, Z.Q.; Zhang, Y.L. Effects of cantharidin on four metabolizing enzymes and PPO in Mythimna separata (Walker) (Lepidoptera Noctuidae). Acta Entomol. Sin. 2010, 53, 870-875.

21. Mao, YB.; Cai, W.J.; Wang, J.W.; Hong, G.J.; Tao, X.Y.; Wang, L.J.; Huang, Y.P.; Chen, X.Y. Silencing a cotton bollworm P450 monooxygenase gene by plant mediated RNAi impairs larval tolerance to gossypol. Nat. Biotechnol. 2007, 25, 1307-1313.

22. Chen, L.; Hall, P.R.; Zhou, X.E.; Ranson, H.; Hemingway, J.; Meehan, E.J. Structure of an insect delta-class glutathione $S$-transferase from a DDT-resistant strain of the malaria vector Anopheles gambiae. Acta Crystallogr. D 2003, D59, 2211-2217.

23. Furlong, M.J.; Wright, D.J. Examination of stability of resistance and cross resistance patterns to acylurea insect growth regulators in field populations of diamond back moth, Plutella xylostella from Malaysia. J. Pestic. Sci. 1994, 42, 315-326.

24. Mohan, M.; Gujar, G.T. Local variation in susceptibility of diamondback moth, Plutella xylostella (L.) to insecticides and role of detoxifying enzymes. Crop Prot. 2003, 2, 495-504.

25. Balabaskaran, S.; Chuen, S.S.; Muniandy, S. Glutathione $S$-transferase from the diamondback moth. Insect Biochem. 1989, 19, 435-443.

26. Kao, C.H.; Hung, C.F.; Sun, C.N. Parathion and methyl parathion resistance in diamond back moth (Lepidoptera: Plutellidae) larvae. J. Econ. Entomol. 1989, 82, 1299-1300.

27. Yu, S.J.; Nguyen, S.N. Detection and biochemical characterization of insecticide resistance in the diamond back moth. Pestic. Biochem. Physiol. 1992, 44, 74-81.

28. Wu, Y.; Shen, D.J. Character of Fenvalerate resistance in Helicoverpa arraigera (Hubner) from China. Resistant Pest Manag. Newsl. 1996, 8, 25-27.

29. Kostaropoulos, I.; Papadopoulos, A.I.; Metaxakis, A.; Boukouvala, E.; Papadopoulou-Maurkidou, E. Glutathione $S$-transferase in the defense against pyrethroids in insects. Insect Biochem. Mol. Biol. 2001, 31, 313-319.

30. Soderlund, D.M.; Hessney, C.W.; Helmuth, D.W. Pharmacokinetics of cis- and trans-substituted pyrethroids in the American cockroach. Pestic. Biochem. Physiol. 1983, 20, 161-168.

31. Hayes, J.D.; Wolf, C.R. Role of Glutathione Transferases in Drug Resistance. In Glutathione Conjugation: Mechanisms and Biological Significance; Sites, H., Ketter, B., Eds.; Academic Press: London, UK, 1988; pp. 3150-355.

32. Harold, J.A.; Ottea, J.A. Toxicological significance of enzyme activities in profenofos-resistant tobacco budworms, Heliothis virescens (F.). Pestic. Biochem. Physiol. 1997, 58, 23-33. 
33. Vontas, J.G.; Small, G.J.; Hemingway, J. Glutathione $S$-transferases as antioxidant defense agents confer pyrethroid resistance in Nilaparvata lugens. Biochem. J. 2001, 357, 65-72.

34. Ahmed, M.; McCaffery, A.R. Elucidation of detoxification mechanisms involved in resistance to insecticides against third instar larvae of a field selected strain of Helicoverpa armigera with the use of synergists. Pestic. Biochem. Physiol. 1991, 41, 41-52.

35. Sambrook, J.; Russel D.W. Molecular Cloning: A Laboratory Manual; Cold Spring Harbor Laboratory Press: New York, NY, USA, 1989; pp. 18.1-18.85.

36. Booth, G.M.; Connor, J.; Metcalf, R.A.; Larsen, J.R. A comparative study of the effects of selective inhibitors on esterase isozymes from the mosquito Anopheles punctipennis. Comp. Biochem. Physiol. B 1973, 44, 1185-1195.

37. Pfaffl, M.W. A new mathematical model for relative quantification in real-time RT-PCR. Nucleic Acids Res. 2001, 29, 2002-2007.

38. Sali, A.; Blundell, T.L. Comparative protein modelling by satisfaction of spatial restraints. J. Mol. Biol. 1993, 234, 779-815.

39. Thompson, J.D.; Gibson, T.J.; Plewniak, F.; Jeanmougin, F.; Higgins, D.G. The ClustalX windows interface: Flexible strategies for multiple sequence alignment aided by quality analysis tools. Nucleic Acids Res. 1997, 24, 4876-4882.

40. Chen, V.B.; Arendall, W.B., 3rd; Headd, J.J.; Keedy, D.A.; Immormino, R.M.; Kapral, G.J.; Murray, L.W.; Richardson, J.S.; Richardson, D.C. MolProbity: All-atom structure validation for macromolecular crystallography. Acta Crystallogr. D 2010, D66, 12-21.

41. GOLD, version 5.1; The Cambridge Crystallographic Data Centre (CCDC): Cambridge, UK, 2012.

42. DeLano, W.L. The PyMol Molecular Graphics System; DeLano Scientific: Palo Alto, CA, USA, 2010.

43. Ivetic, T.V.; Hrvacic, B.; Bosnar, M.; Cuzic, S.; Bosnjak, B.; Erakovic, H.V.; Glojnaric, I. Cantharidin-induced inflammation in mouse rar model for translational research of novel anti-inflammatories. Tranl. Res. 2012, 160, 137-145.

44. Macrae, C.F.; Bruno, I.J.; Chisholm, J.A.; Edgington, P.R.; McCabe, P.; Pidcock, E.; Rodriguez-Monge, L.; Taylor, R.; Van de streek, J.; Wood, P.A. Mercury CSD 2.0-New features for the visualization and investigation of crystal structures. J. Appl. Cryst. 2008, 41, 466-470.

(C) 2013 by the authors; licensee MDPI, Basel, Switzerland. This article is an open access article distributed under the terms and conditions of the Creative Commons Attribution license (http://creativecommons.org/licenses/by/3.0/). 